\title{
Pelatihan Ecoprint Teknik Pounding Bagi Guru-Guru PAUD Haqiqi di Kota Bengkulu
}

\author{
Steffanie Nurliana ${ }^{*}$, Wiryono ${ }^{2}$, Hery Haryanto ${ }^{3}$, Syarifuddin $^{4}$ \\ ${ }^{134}$ Jurusan Biologi FMIPA Universitas Bengkulu \\ ${ }^{2}$ Jurusan Kehutanan Fak. Pertanian Universitas Bengkulu. \\ E-mail*: snurliana@unib.ac.id
}

Article History:
Received: Septembe
2021
Revised: September
2021
Accepted: Oktober
2021
Available online:
Desember 2021

\section{Kata Kunci:}

pemanfaatan

tumbuhan, pewarnaan alami, zat warna alam

\begin{abstract}
Abstrak: Teknik ecoprint merupakan suatu pencetakan bentuk dan warna pada media, seperti kain, kertas, kulit, dan keramik untuk dengan menggunakan zat warna dari tumbuhan-tumbuhan. Kegiatan pengabdian masyarakat inidilaksanakan untuk: memberikan pelatihan ketrampilan ecoprint teknik pounding, memberi wawasan botani tentang daun-daun yang memiliki jejak bagus dengan ecoprint teknik pounding, dan memberi wawasan kewirausahaan agar peserta dapat memanfaatkan ecoprint teknik pounding untuk memperoleh tambahan penghasilan. Kegiatan pengabdian ini dilakukan di Paud Haqiqi, Kelurahan Pematang Gubenur, Kecamatan Muara Bangkahulu, Kota Bengkulu dengan metoda ceramah dan praktek langsung. Kegiatan diikuti oleh 13 guru Paud. Semua peserta berhasil mengerjakan ecoprint teknik pounding dengan baik pada tas kain, yang kemudian dibawa pulang oleh masing-masing peserta. Kegiatan pengenalan Ecoprint diliput oleh wartawan koran Rakyat Bengkulu dan dimuat di Koran Rakyat Bengkulu, dimuat di webwww.rakyatbengkulu.com.www.duniahij au.com, dan diupload di Youtube. Perlu diberikan pelatihan lanjutan dengan teknik ecoprint yang lain.
\end{abstract}




\section{Pendahuluan}

Indonesia memiliki keragaman jenis tumbuhan yang dimanfaatkan masyarakat, terutama di pedesaan, untuk berbagai keperluan, antara lain sebagai pewarna makanan (Wiryono dkk 2019). Dalam beberapa dasawarsa terakhir ini, zat warna tumbuhan juga digunakan untuk membuat karya seni yang disebut ecoprint dengan corak dan warna khas sesuai dengan jenis tumbuhan yang dipakai (Flint, 2021). Selain tekstil, media lain yang bisa digunakan untuk membuat ecoprint adalah kertas, kulit dan keramik.

Ecoprint berasal dari kata eco dan print. Eco merupakan penggalan dari kata ecology atau ecosystem, yang mulai digunakan oleh banyak orang sejak kesadaran lingkungan meningkat, untuk menunjukkan keterkaitan suatu aktifitas dengan keselamatan lingkungan (Wali, 1995). Print yang berarti pencetakan. Jadi Ecoprint merupakan sebuah proses pencetakan yang ramah terhadap lingkungan karena menggunakan bahan pewarna alami.

Bahan yang digunakan pada teknik ecoprint dari tumbuh-tumbuhan adalah akar, batang, daun dan bunga. Bahan tanaman yang berbeda dan jenis tanaman yang berbeda dapat memberikan warna dan jejak yang berbeda pula (Saraswati dkk. 2019). Dengan tingginya keragaman jenis tumbuhan, hasil dari ecoprint beragam pula. Karena ecoprint dikerjakan secara individual, tidak massal, maka hasil dari ecoprint tidak seragam satu sama lain sebagaimana percetakan dengan mesin atau digital. Oleh karena itu hasil karya ecoprint dapat menunjukkan orisinalitas karya seniman atau perancang (Nurcahyanti and Septiana, 2018). Teknik ecoprint dapat dikombinasikan dengan teknik batik yang sudah dikenal masyarakat untuk menciptakan kreasi yang baru (Sedjati, 2019).

Ada tiga teknik dasar ecoprint, yaitu pemukulan atau pounding, perebusan atau boiling dan kukus atau steaming (Simanungkalit, 2020). Teknik pounding adalah teknik yang paling mudah dilakukan. Pada teknik pounding, proses mentransfer bentuk dan warna tumbuhan pada kain dilakukan dengan memukul tumbuhan pada kain yang diletakkan pada permukaan datar. 
Teknik merebus pada ecoprint dilakukan dengan cara sebagai berikut: 1) kain discouring dan dimordanting, 2) kemudian, kain tersebut dibentangkan sehingga posisi kain rata dan mendatar, 3) selanjutnya, bahan tumbuhan ditempelkan pada kain, 4) kain yang telah diletakkan bagian-bagian tumbuhan lalu dilapisi dengan plastik, 5) digulung dengan pipa hingga rapat, 6) kemudian diikat dengan benang atau tali, dan akhirnya 7) kain direbus selama 1-2 jam. Teknik mengukus mirip dengan teknik merebus, tetapi kain tidak direbus melainkan hanya dikukus dan posisi kain tidak terendam air secara langsung. (Simanungkalit, 2020).

Kegiatan pembuatan ecoprint di Indonesia sudah banyak dilakukan oleh pecinta ecoprint, namun belum banyak dikenal oleh masyarakat umum, tidak seperti kerajinan batik. Untuk pengenalan ecoprint kepada masyarakat telah dilakukan beberapa kegiatan pengabdian oleh beberapa dosen perguruan tinggi, antara lain di Kabupaten Agam (Suci, 2019), di Makasar (Irmayanti dkk, 2019), di Semarang (Nurohim dkk, 2020) dan di Kudus (Nafiah dan Husna, 2021). Namun, sampai saat ini di Provinsi Bengkulu belum ada kegiatan pengenalan ecoprint kepada masyarakat. Oleh karena itu, kegiatan pelatihan ecoprint dengan teknik pounding kepada guru-guru PAUD ini dilakukan dengan tujuan: memberikan pelatihan ketrampilan ecoprint teknik pounding, memberi wawasan botani tentang daun-daun yang memiliki jejak bagus, dan memberi wawasan kewirausahaan agar peserta dapat memanfaatkan ecoprint teknik pounding untuk mengembangkan hobi dan memperoleh tambahan penghasilan. Teknik pounding dipilih karena teknik ini relatif mudah dilakukan, tidak memerlukan alat dan bahan yang mahal.

\section{Metode}

\section{Lokasi, waktu dan sasaran}

Kegiatan pengabdian pelatihan ecoprint dengan teknik pounding dilaksanakan di Paud Haqiqi, Kelurahan Pematang Gubernur, Kecamatan Muara Bangka Hulu, Kota Bengkulu, pada tanggal 29 Juni 2021. Sasaran kegiatan adalah guru-guru Paud Haqiqi sebanyak 13 orang dengan harapan mereka dapat menularkan ketrampilan ini kepada anak didiknya. 


\section{Bahan dan alat}

Dalam kegiatan pelatihan ini digunakan bahan-bahan berupa daun tanaman babandotan (Ageratum sp), papaya Jepang (Cnidoscolus

aconitifolius), kenikir (Cosmos caudatus), red panama (Hibiscus acetosella), miana (Plectranthus scutellarioides), dan kain (Gambar 1). Alat yang dipakai adalah palu kayu (Gambar 1).

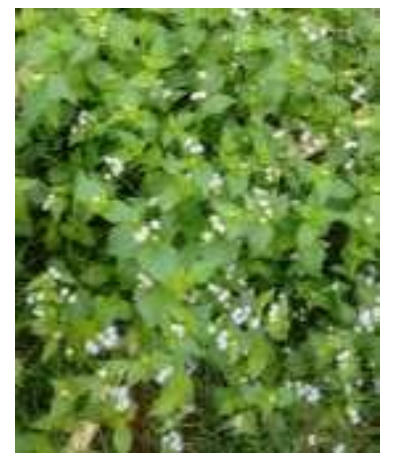

Ageratum sp

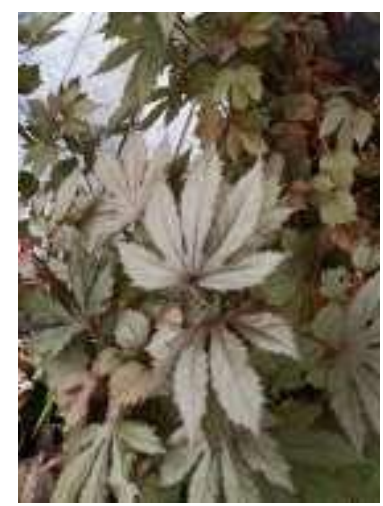

Hibiscus acetosella

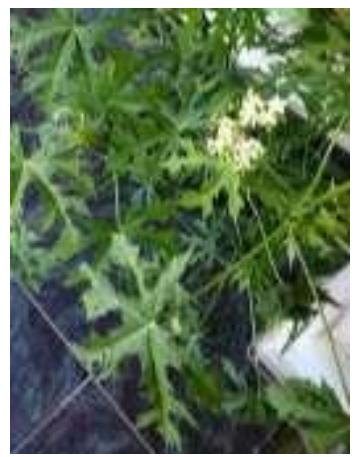

Cnidoscolus aconitifolius

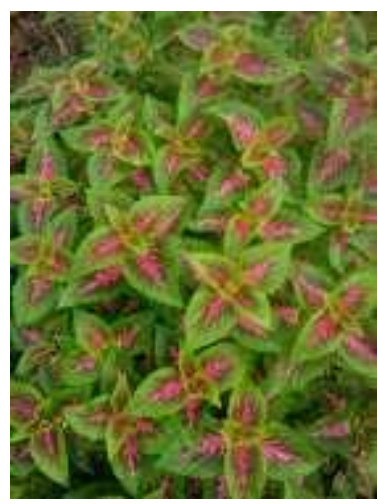

Plectranthus scutellarioides

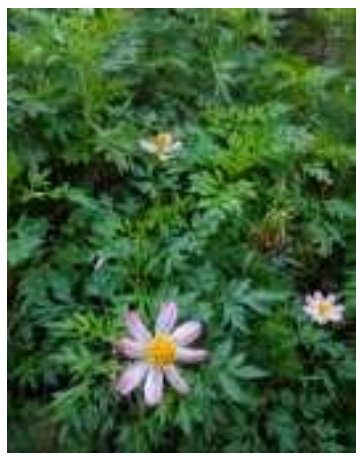

Cosmos caudatus

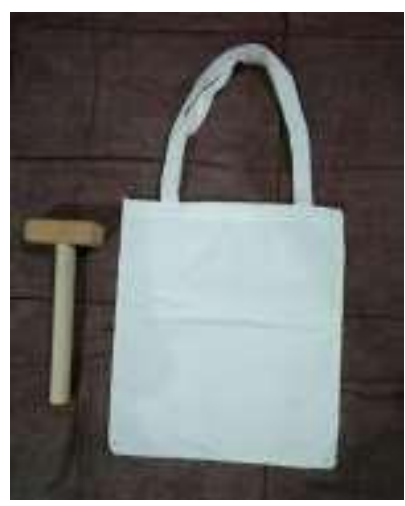

Palu dan tas kain

Gambar 1. Daun, tas kain dan palu yang digunakan untuk pembuatan ecoprint dengan teknik pounding 


\section{Prosedur}

Pelatihan dilakukan dengan metoda ceramah yang diikuti dengan peragaan dan praktek langsung pembuatan ecoprint teknik pounding oleh setiap peserta. Tahapan yang dilakukan adalah sebagai berikut:

A. Persiapan media/tas kain/totebag.

Tas kain (totebag) yang dijadikan media pounding dicuci dengan larutan 5 gram TRO dalam 2 liter air. Selanjutnya tas kain dibilas dengan air bersih, lalu dikering-anginkan. Setelah kering tas tersebut siap untuk diecoprint. Metoda ini merupakan penyederhanaan dari metoda yang lebih lengkap, yaitu kain tersebut direndam dulu dalam larutan tawas selama satu malam.

B. Persiapan daun :

Daun-daun yang dibutuhkan diambil dari kebun bersama tangkai daunnya. Tangkai daun tersebut direndam dalam air untuk mempertahankan kesegarannya.

\section{Tahapan pembuatan ecoprint teknik pounding}

Tas kain dibentangkan di atas meja atau lantai yang sudah diberi alas kertas atau kain bersih. Sementara itu, disiapkan lembaran plastik yang dipotong dengan ukuran kurang lebih $2 \mathrm{~cm}$ lebih kecil dari ukuran tas kain, baik pada sisi panjang maupun lebar totebag. Pada setiap tas kain yang terbentangdimasukkan satu lembar potongan plastik. Kemudian,tas kain tersebut dirapikan kembali. Setelah itu, daun-daun yang sudah dilap bersih ditata di atas kain dengan disain penataan daun sesuai dengan yang diinginkan. Selanjutnya, di atas daun diberi lembaran plastik transparan agar ketika daun dipukul-pukul, daun tidak melekat pada palu. Pemukulan daun dilakukan dengan palu kayu dengan hentakan yang stabil agar zat warna daun melekat dan motif daun tercetak kuat di tas kain. Apabila satu daun sudah selesai, pemukulan dilanjutkan dengan daun-daun berikutnya sehingga semua daun tercetak jelas dan rapi di atas tas kain sesuai dengan disain yang sudah direncanakan. Setelah pemukulan selesai, daun dilepaskan dan plastik dikeluarkan dari tas kain. Selanjutnya, tas kain tersebut didiamkan dan 
diangin-anginkan. Karena terbatasnya waktu, pelatihan ecoprint dihentikan sampai di sini. Namun peserta diberitahu bahwa jika mereka menginginkan hasil yang lebih baik, tas kain yang sudah diangin-anginkan selama satu sampai tiga hari perlu difiksasi dengan cara direndam dalam larutan tawas selama satu jam agar warna tidak luntur dan bertahan lama. Selanjutnya, tas kain dibilas tanpa diperas, kemudian diangin-anginkan kembali sampai kering. Terakhir, tas kain disetrika agar rapi dan siap untuk dipakai.

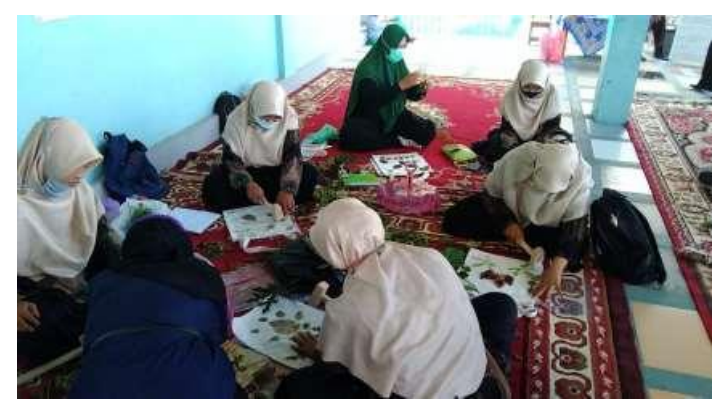

Gambar 2. Peserta pelatihan sedang mengerjakan pounding pada tas kain.

\section{Hasil}

Pelatihan berjalan dengan baik. Semua peserta dapat mengerjakan ecoprint dengan teknik pounding pada tas kain. Daun-daun yang digunakan memberikan jejak bentuk dan warna yang khas, berbeda satu sama lain. Daun papaya Jepang menghasilkan jejak berwarna hijau terang. Daun red panama menghasilkan jejak ungu. Daun kenikir menghasilkan warna hijau gelap. Daun miana menghasilkan warna merah kuning kehijauan (Gambar 3).
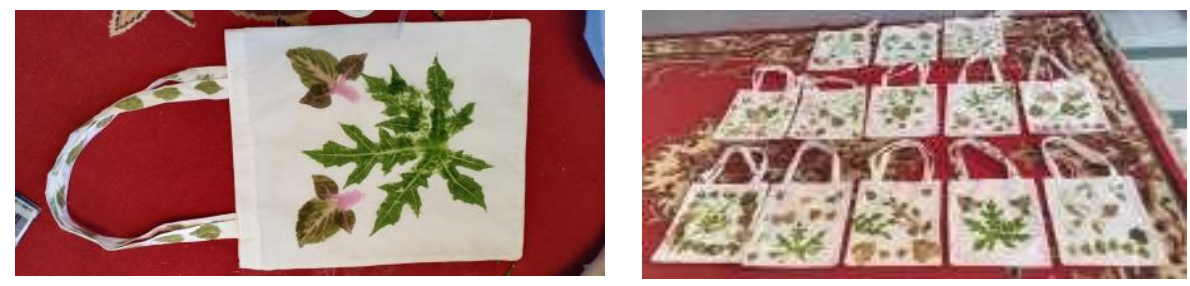

Gambar 3. Hasil dari ecoprint dengan teknik pounding yang dibuat peserta pelatihan. 
Tas hasil ecoprint diberikan kepada masing-masing peserta untuk dibawa pulang. Dari wawancara diketahui bahwa peserta pelatihan merasa puas dengan hasil yang diperolehnya. Mereka menginginkan pelatihan ecoprint lanjutan dengan teknik kukus dan rebus. Ketrampilan membuat ecoprint tersebut akan dipraktekkan di rumah, namun mereka belum berminat untuk menjual produk ecoprint mereka karena ingin dipakai dan digunakan sendiri. Kegiatan pelatihan ini diliput oleh harian Semarak Bengkulu dan dipublikasi secara online pada tanggal 3 Juli 2021 (https://rakyatbengkulu.com/2021/07/03/mengenal-kerajinan-tangan-ramahlingkungan-dosen-mipa-unib-kenalkan-teknik-ecoprint-untuk-masyarakat/).

Kegiatan pelatihan juga diunggah di Youtube dengan judul "Ecoprint for Kindergarten Teachers” dengan link:

(https://www.youtube.com/watch?v=UwA4gVMYEJo)

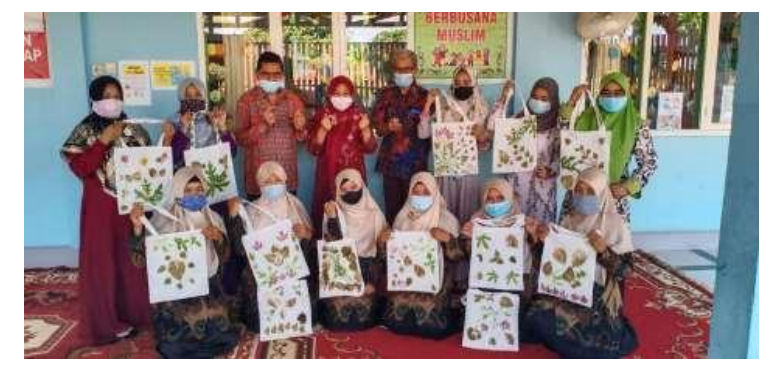

Gambar 4. Tim pengabdian dan peserta menunjukkan hasil pelatihan (Sumber: Rakyat Bengkulu)

\section{Diskusi}

Pembuatan ecoprint dengan teknik pounding berhasil dengan baik karena teknik pounding sangat mudah dilakukan. Jenis-jenis tumbuhan yang digunakan menghasilkan jejak yang kuat dengan bentuk dan warna bervariasi sesuai dengan pigmen yang dikandungnya. Tumbuhan tingkat tinggi memiliki pigmen yang dapat dikelompokkan menjadi beberapa grup, yaitu: 1) chlorophylls yang memberi warna hijau, 2) carotenoids (carotenes, xanthophylls) memberi warna kuning, oranye dan merah, 3) flavonoids 
(chalcones, anthocyanins, flavones, flavonols) yang memberi warna merah muda, kuning pucat, hitam, biru dan merah, dan 4) betalains (betaxanthin, betacyanin) yang menghasilkan warna kuning dan merah (Młodzińska, 2009). Pewarna alami dari tumbuhan sudah digunakan orang sejak beberapa ribu sebelum Masehi, sebelum pewarna sintetis ditemukan (Gilbert and Cooky, 2001). Jenis tumbuhan yang digunakan dalam pengabdian ini adalah jenisjenis sayuran dan tanaman hias yang mudah didapat. Dari 5 jenis tanaman, 3 jenis meninggalkan jejak berwarna hijau, yaitu pepaya Jepang (Cnidoscolus aconitifolius), kenikir (Cosmos caudatus) dan babandotan (Ageratum sp), menunjukkan bahwa yang dominan adalah pigmen khlorofil. Sementara itu, daun red panama (Hibiscus acetosella) menghasilkan jejak berwarna merah jingga karena pigmen antosianin yang dikandungnya (Kangthin dkk. 2021). Demikian juga dengan daun miana (Plectranthus scutellarioides) yang juga mengandung antosinanin (Puspita dkk. 2018) selain khlorofil menghasilkan jejak merah kuning kehijauan, Jumlah jenis tanaman yang digunakan dalam penelitian ini hanya 5, sehingga variasi bentuk dan warna jejaknya pada kain tidak terlalu banyak. Pada pelatihan selanjutnya perlu digunakan lebih banyak jenis tanaman untuk mendapatkan variasi yang lebih banyak.

Ecoprint teknik pounding mudah dilakukan, tetapi jejak yang dihasilkan kurang tahan jika kain dicuci. Teknik kukus dan rebus menghasilkan jejak yang lebih tahan, namun diperlukan bahan dan alat yang lebih banyak dengan konsekuensi biaya yang lebih banyak dan ketrampilan yang lebih tinggi. Kain yang digunakan dalam pengabdian ini adalah kain katun yang mudah menyerap warna. Namun untuk ecoprint teknik kukus dan rebus, kain sutera pada umumnya menghasilkan jejak yang lebih baik. Jika peserta memiliki waktu luang untuk mengerjakan ecoprint pada berbagai produk kain, misalnya kerudung, masker, tas, dan baju dengan berbagai teknik mereka dapat menghasilkan karya seni yang dapat dimanfaatkan untuk mendapatkan penghasilan tambahan.

Peserta pelatihan dalam kegiatan ini semuanya berjenis kelamin perempuan dan berpendidikan cukup tinggi. Sesuai dengan profesinya sebagai guru, diharapkan peserta pelatihan dapat mengajarkan ketrampilan ecoprint ini 
kepada anak didiknya sebagai kegitan untuk mengenal tumbuh-tumbuhan dan membuat karya seni sederhana.

\section{Kesimpulan}

Semua peserta pelatihan dapat mengerjakan ecoprint teknik pounding dengan baik. Pelatihan ini perlu dilanjutkan dengan pelatihan ecoprint dengan teknik kukus dan rebus yang menghasilkan jejak dan warna yang lebih kuat.

\section{Pengakuan}

Kami mengucapkan terima kasih kepada Ibu Lirwana sebagai Kepala Paud Haqiqi yang telah membantu memfasilitasi kegiatan ini sehingga kegiatan berjalan dengan lancar, dan kepada LPPM Universitas Bengkulu yang telah menugaskan kami untuk melakukan kegiatan pengabdian kepada masyarakat di Paud Haqiqi.

\section{Daftar Referensi}

Gilbert, K.G. \& Cooke, D.T.(2001). Dyes From Plants: Past Usage, Present Understanding And Potential. Plant Growth Regulation 34: 57-69

Irmayanti, Suryani, H \& Megawati, R. (2020). Pemanfaatan Bahan Alami Untuk Pembuatan Ecoprint Pada Peserta Kursus Menjahit Yayasan Pendidikan Adhiputeri Kota Makassar. PENGABDI: Jurnal Hasil Pengabdian Masyarakat 1 (1): 44-49

Kangthin, K. , Naratjarunsap, R., Puttaruk, P., Wisidsri, N., Jamkom, K., \& Thungmungmee, S. (2021). Pigment Stability In Chaba Maple (Hibiscus Acetosella Welw. Ex Hiern.) Petals Extract As Natural Food And Cosmetic Colorants . Songklanakarin J. Sci. Technol.43 (2): 460464

Młodzińska, E. (2009). Survey Of Plant Pigments: Molecular And Environmental. Determinants Of Plant Colors ACTA BIOLOGICA CRACOVIENSIA Series Botanica 51 (1): 7-16

Nafi'ah, R. \& Husna, A. H. (2021). How To Make Ecoprint On Mask In The Context Of Covid-19 Prevention Based On Eco Green At Hirzu Millati Islamic Boarding School, Singocandi Kudus. Jurnal Pengabdian Kesehatan STIKES Cendekia Utama Kudus 4 (2): 94-104

Nurcahyanti, D \& Septiana, U. (2018. Handmade Eco Print As A Strategy To Preserve The Originality Of Ria Miranda's Designs In The Digital 
Age. MUDRA Journal Of Art And Culture 33(3): 395-400.

Nurohim, Zazuli, A.I., \& Hidayah, F.F. (2020). Membangun Desa Ekonomi Mandiri Melalui Batik Ecoprint Di Rejosari Kabupaten Kudus. Building Independent Economic Village Through Batik Eco-Printing In Rejosari Kudus District. Prosiding Seminar Nasional Unimus Vol 3:68-76

Puspita, D., Tjahyono, Y.D., Samalukang, Y., Toy, B.A.I., \& Totoda, N.W., (2018). Produksi Antosianin Dari Daun Miana (Plectranthus Scutellarioides) Sebagai Pewarna Alami [Anthocyanin Production From Miana Leaves (Plectranthus Scutellarioides) As Natural Pigment]. Pro Food (Jurnal Ilmu Dan Teknologi Pangan) 4 (1): 298303

Saraswati, R., Susilowati, M.H.D., Restuti, R.C., Dan Pamungkas, F.D. 2019. Pemanfaatan Daun Untuk Ecoprint Dalam Menunjang Pariwisata. Departemen Geografi, FMIPA, Universitas Indonesia.

Sedjati, D.P. \& Sari, V.T. (2019) Mix Teknik Ecoprint Dan Teknik Batik Berbahan Warna Tumbuhan Dalam Penciptaan. CORAK Jurnal Seni Kriya 8 (1): 1-11

Simanungkalit, Y.S. 2020. Teknik Ecoprint Dengan Memanfaatkan Limbah Mawar (Rosa Sp.) Pada Kain Katun. Skripsi. Fakultas Teknik, UNNES.

Suci, P.H. (2019). Pelatihan Pembuatan Motif Kain Dengan Metode Ecoprint Di Nagari Tabek Panjang Kecamatan Baso Kabupaten Agam. Training Of Fabric Motif Using Ecoprint Method On Nagari Tabek Panjang Kecamatan Baso Kabupaten Agam. Journal Of Community Service 1 (1): 200-207

Wiryono, Sriwahyuni, Winanda, G.A., Saprinurdin \& Nurliana, S. (2019). The Diversity Of Useful Plants And Botanical Knowledge Of The Rejang Tribe In Kepahiang District, Bengkulu Province, Indonesia. Biodiversitas 20 (12): 3599- 3607. 